\section{Switchgear Practice}

By Arthur Arnold. Pp. iv $+238+27$ plates. (London : Chapman and Hall, Ltd., 1942.) 22s. net.

AOOK on this subject, planned as this one is, $A$ has been needed for a long time, for while there is an extensive literature in the form of articles and papers presented before the professional engineering institutions, contributions in book form are relatively scanty. Those which have appeared have generally been written by and for switchgear designers, so that one having a particular appeal for the user-engineer fills a distinct gap which has existed in the technological book world.

The scope of the work is wide, ranging as it does from motor starters to high-rupturing capacity circuit-breakers. The treatment accorded to it is based upon a presentation of the main principles controlling the selection of suitable gear for the many purposes which arise in practice; design data and constructional details are omitted, as being outside the conception of the book. The first four chapters deal with D.c. breakers, motor starters, controllers and switchboards, the rest of the book describing A.c. breakers of small and medium sizes and those for heavy-duty service, A.c. busbars, are control devices, interlocks, testing, switchgear protective devices, instrument and control boards, lightning arresters, fire prevention and protection, and oil-less circuit breakers.

There is a surprising omission of reference to the pioneer research and development done by the British Electrical and Allied Industries Research Association on gas-blast circuit-breaker development, and no record in the bibliography of the published work of Wedmore, Whitney and Bruce of that body. Such work may not be 'recent', but it is too funda. mental to be ignored, and British engineers have led the way in this important phase of large power control. Methods of calculating network fault currents might also, with advantage, have been given in the book-it is a feature of prime importance to the user and one which he needs to predetermine when specifying the requirements of a circuit breaker. The book, however, constitutes a useful survey of modern switchgear practice and it should enjoy a ready acceptance by operating engineers.

\section{Air Navigation}

British Empire edition, by Lieut.-Comdr. P. V. H. Weems. Revised and edited by Arthur J. Hughes and P. F. Everitt. Second edition. Pp. xxi+519. (London: McGraw-Hill Publishing Co., Ltd. ; New York: McGraw-Hill Book Co., Inc., 1942.) 35s.

A S a practical manual of air navigation, this book A can be thoroughly recommended. It describes the methods of navigation by pilotage, dead reckon. ing, radio position finding and celestial observation, with a comprehensive account of the instruments employed and of the various tables for facilitating the determination of position. It contains little in the way of mathematics and does not go at all deeply into the theory of the methods. The outlook is essentially practical rather than theoretical. An unusual feature in a work of this sort, but one of undoubted value for the air navigator, is an excellent outline of meteorology by Dr. Sverre Peterssen. The book contains a large number of figures, diagrams and illustrations of various instruments and forms a useful work of reference.

There are a few statements which are inaccurate or misleading ; but it is not correct, as stated on p. 75, that a magnetic compass points towards the north magnetic pole, nor is it true that the changes with time in the magnetic variation are due primarily to the movement of the earth's magnetic poles. The statement on p. 330 that "better navigation can now be done by using two good second-setting watches, checked daily, than is possible with two or three high-class chronometers when these are checked only occasionally", is not pertinent to the relative time-keeping properties of watches and chronometers. In these days when radio time signals are generally available, there is no reason why chronometers should be checked only occasionally. Though a good performance can be expected from a high-grade watch, this affords no justification for belittling the better performance of which a chronometer is capable.

H. S. J

Food, Health, Vitamins

By Prof. R. H. A. Plimmer and Violet G. Plimmer. Ninth edition. Pp. viit 193. (London, New York and Toronto : Longmans, Green and Co., Ltd., 1942.) 7s. $6 d$.

\section{Vitamins and Minerals for Everyone}

By Alida Frances Pattee. Pp. xviii + 242. (New York and London: Putnam and Co., Inc., 1942.) $10 s$. net.

" COOD, HEALTH, VITAMINS" has reached its ninth edition and is so familiar as to need little further notice. It has made its way on merit and to-day is acknowledged to be an excellent introduction to the subject of nutrition. New material has been added which gives the results of various wartime nutritional experiments, and the numerous tables have been overhauled and brought up to date.

"Vitamins and Minerals for Everyone" is a queer mixture. It has been written and arranged "for both the profession and the laity", and has catered happily for neither. The laity is provided for by some dramatic interludes which remind one of the commentaries of a Wild West serial produced in Hollywood. The contribution "for the profession" includes an account of the part played by vitamins and trace elements in human nutrition together with a valuable appendix of relevant nutritional tables.

Biology Staining Schedules for First Year Students By R. R. Fowell. Pp. 20. (Swansea : The Author, Swansea Technical College, 1943.) 1s.6d.

7 HIS little laboratory manual presents in a clear and compact form the practical directions necessary to enable the student to master a limited number of staining techniques, which have been chosen as those most suitable for students or senior pupils working through courses for the Intermediate B.Sc. or B.Pharm., First Medical or Higher Certificate.

A preliminary section deals with such matters as the classes and uses of stains. Tables are given of the chief staining reagents and some advice on staining, which might have been advantageously extended. This is followed by five pages of botanical methods and seven pages of zoological methods, mostly variants of hæmatoxylin methods, but including smears and whole mounts.

Modest though the booklet is, it is well suited to the type of student for whom it is intended. Far too little work is done on permanent preparations by junior students, and this booklet should stimulate improvement in this respect. R. C. McLEAN. 